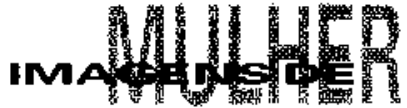

\section{Marza Sicuro}

Psteóloga Clínica. Mestre em Psicologie Social e da Personalidade pela PUCRS. Coordenadora de Ensino do Instituto
Fernando Pessoa. Forto Alegre, RS

\section{A IMAGEM ENA MULHER}
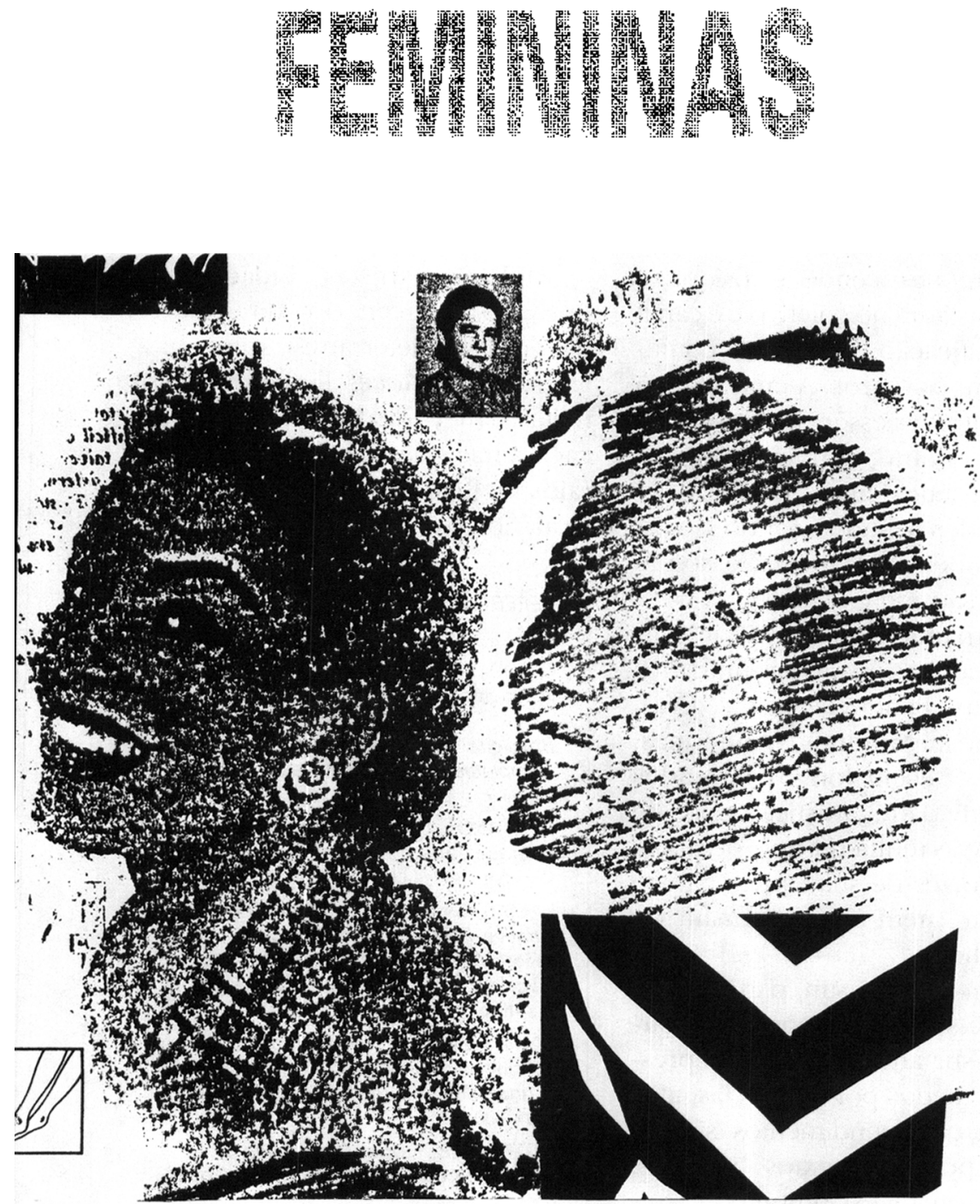

D e forma lenta, a mulher traça e percorre uma trajetória ascendente, buscando igualdade social, profissional e independência econômica. Entretanto, nào são poucas as tentativas de mantei a mulher em seu papel secular de doméstica, ou seja, do lar, sem vivência no mundo mais amplo da participação pública (Friedan, 1963 Novelino, 1988)

O mundo feminino debate-se na pseudodicotomia entre ser esposa/ màe/dona-de-casa ou ser profissional e, neste último caso, ter que fazer a falsa opção pela ausência de uma família ou, pelo menos, de filhos. Ao assumir carreira e maternidade, pode ter culpa, gerada pela idéia de não estar atendendo adequadamente, principalmente, aos filhos, o que é muito enfatizado pela divulgaçào de pesquisas científicas tendenciosas e pelo senso comum de que ninguém substitui a màe em sua divina e natural tarefa de gerar, parir e criar a prole (Kude, 1994)

A socialização e a educaçà formal e informal de meninos e meninas perpetuam a idéia de uma mulher voltada muito mais para o mundo privado. Ainda tem pouca força uma imagem nascente de mulher dedicada também - e bem-sucedida - no mundo mais amplo público, até pouco tempo, de quase total domínio dos homens.

A ênfase atual da relaçà homem/mulher procura estabelecer novos parâmetros de relacionamentos. Entretanto, ainda temos a tendência de colocá-los em primeiro lugar, sempre que refericlos. Politicamente correto seria escrever muIher/homem, mas jă nào estaremos, desta forma, criando outro jargão, 0 negativo de um preconceito? Nossa sociedade já os têm em abundância

As relaçoes entre casais heterossexuais, no aspecto formal de calsamento, está passando por uma verdadeira metamorfose, assim como os setores profissionais permeados pela ocupação feminina. Estas transformaçoes verificam-se através do espaço cada vez maior que as mulheres passaram a reivindicar eocupar, via independência financeira $e$ 
emancipação de comportamentos, agora menos atreladas ao antigo código de posturas, que sempre excluía do linguajar feminino palavras como poder, prazer, liberdade, dignidade e direitos.

Em tempos não tão remotos, o ideal das moças e dos pais destas moças consistia na segurança, obtida através do casamento. Teria um marido que proveria o lar com comidas, roupas, filhos, idéias e decisões. Ela cuidaria da manutenção desse lar, doce lar, com carinho, dedicação, renúncia e sobremesas. O que mais esperar da vida?

Malheiros (1994) observa que "era esse o grande destino sonhado pela mulher-e assim ela era feliz. $O$ mundo que lhe pertencia era 0 mundo do lar. O que acontecia no mundo fora de sua casa não the interessava. Esse mundo era exclusivamente de seu marido" (p.66).

Foi isto o que aprendemos desde pequenas, meninas e também meninos, através das mensagens nada subliminares de nossas famílias .

A transmissão da cultura ocorreu tanto de modo informal (tradições, arte, rituais, crenças), como de modo formal (a partir da escrita). Mais recentemente na nossa História, a civilização vem servindo-se de tecnologias cada vez mais sofisticadas para informação e formação da opinião pública, desde o advento da imprensa. Entretanto, ainda que os meios de comunicação avancem a passos cada vez mais largos, o conteúdo das mensagens difundidas não acompanha tal ritmo.

Referimo-nos particularmente à questão dos papéis sexuais. Embora se fale muito em igualdade, direitos, independência, liberdade sexual, boas condiçôes de trabalho e outros tantos jargões desgastados pela mídia e pouco compreendidos, na realidade é freqüente observar como as mulheres não atingiram ainda todos esses objetivos.

Interessa-nos, especificamente, avaliar se $o$ aspecto de algoz que as mulheres atribuem aos homens é criação e responsabilidade exclusiva deles, ou se 'também não está constituído de intervenções femini- nas, projetadas neles. Os homens são vistos como impedidores do crescimento da mulher e, sem dúvi$\mathrm{da}$, grupos masculinos, em diferentes momentos da História, fizeram por merecer essa imagem. Entretanto, ao admitir-se que grande parte das diferenças se deu por questōes culturais, e não apenas biológicas, cabe-nos observar como é transmitida a cultura (Paiva, 1990; RochaCoutinho, 1994).

Do ponto de vista psicanalítico, entende-se que a formação do caráter de uma pessoa se processa nos primeiros anos da infância, quando ocorre a estruturação da personalidade. Praticamente todos os recursos emocionais e preceitos morais que usamos ao longo da vida, adquirimos quando éramos bem pequenos $\dot{e}$, conseqüentemente, convivíamos a maior parte do tempo com figuras femininas: mãe, avós, madrinha, amigas da mãe, tias, babás, empregada doméstica, tia da creche, professoras ou vizinhas. Ou seja, muito dos preconceitos que assimilamos, prejudiciais à mulher, ouvimos por intermédio de uma delas.

Assim, imbuídas por uma curiosidade, pesquisamos se estes elementos de educação tradicionais ainda podem ser encontrados em revistas femininas, aparentemente conservadoras, bem como em revistas femininas que se declaram mais comprometidas com um papel de mulher arrojado e moderno. Vamos a elas.

Na chamada imprensa feminina, mulheres editam para mulheres $\mathrm{e}$ ocupam, então, um papel de interlocutoras do pensamento feminino para um público muito amplo (Buitoni, 1986).

No Brasil, os referenciais de imprensa para as mulheres são as revistas Claudia e Nova. Ambas, apesar de dirigidas a um público diferente no que tange à faixa etária de suas leitoras, apresentam uma proposta renovadora semelhante: de moldar uma nova mulher, apoiada nos padrōes pós-movimento feminista. Seus artigos suscitam vários questionamentos, como, por exemplo, que as mulheres saiam do uni- verso predominantemente doméstico e se modernizem, mas o teor destes textos apontam uma pseudoemancipação, numa leitura superficial (Mascaro, 1982).

Afligidas por estas suposições, passamos ao exame dessas revistas. Será que as receitas culinárias nâo foram substituídas por receitas de vida? Isto porque uma primeira leitura remete-nos à idéia de que Claudia procura ensinar como a mulher deve portar-se no âmbito doméstico, enquanto que Nova prepara a mulher para enfrentar o mundo profissional, mas parece que as duas trazem, em suma, a mesma mensagem: agrade aos homens! Mas será que é isso mesmo? Assim, pode ser perguntado:

1. Como as revistas apresentam os novos papéis da mulher?

2. As mulheres, quando no comando da redação de uma revista para mulheres, apresentam/representam os papéis tradicionais atribuídos às mulheres?

3. Ou apresentam uma proposta libertadora, no sentido de deixar de vez o estereótipo de mulher?

Desejando, então, identificar o modo como sâo transmitidos os papéis sexuais através da imprensa escrita por mulheres para mulheres no Brasil, foram escolhidos os editoriais das revistas Claudiae Nova, no período de 1981 a 1990 , que foram submetidos à análise de conteúdo, segundo Bardin (1977).

A revista Claudia tem um público-alvo de classe média e alta e se dirige a mulheres cronologicamente mais maduras, geralmente casadas, mães e que se dedicam ao lar. A revista Nova pretende representar a voz de um tipo de mulher das mesmas classes sociais, mas mais jovem, geralmente solteira, ou divorciada, e que trabalha fora de casa. O principal interesse ao compará-las é verificar se Claudia e Nova representam realmente imagens distintas de mulher, ou se na realidade elas são bastante similares, embora se proponham a apresentar propostas diversificadas quanto ao papel da mulher na sociedade atual. 
Os resultados permitem apresentar o seguinte quadro-resumo das categorias e subcategorias oritundas dos editoriais das revistas.

\section{Quadro-resumo das categorias e sub-categorias referentes aos temas dos editoriais das revistas Claudia e Nova}

\section{Mundo Doméstico}

\subsection{Ela/Ele/filhas e Filhos \\ - Beleza \\ - Saúde \\ - Moda \\ - Cuidados pessoais \\ 1.2. Casa

$$
\begin{aligned}
& \text { - Decoraçáo } \\
& \text { - Culinaria } \\
& \text { - Festas }
\end{aligned}
$$

1.3. Ela/Ele

- Famila

- Vida a dois

- Sexualidade

- Mundo Feminino

- Mundo Masculino

1.4. Ela/Economia

- Dinheiro

\section{\& 2 Mundo Externo ao Lar}

2.1. Emancipaçào feminina

2.2. Renovaçāo

2.3. Lazer

2.4. Cultura

- Literatura

- Arte

2.5. Politica

2.6. Planeta

2.7. Misticismo

2.8. Sociedade

2.9. Trabalho

2.10. Humorismo

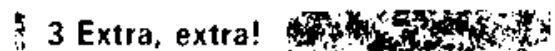

- Revista
O editorial é a divisào mais nobre de uma publicação: é a parte na qual a revista expressa sua opinião. Os editoriais tradicionais da imprensa feminina concentram-se em torno da moda, beleza, cozinha e decoração, e, mais recentemente, sexualidade e trabalho.

As revistas analisadas apresentam em seus editoriais temas semelhantes, que podem ser agrupados em 3 grandes blocos de assuntos: mundo doméstico, mundo externo ao lar e tópicos da própria revista.

E, embora constituídos, por vezes, de unidades diferentes entre Claudia e Nova, o que prevalece é o tema da responsabilidade da mulher como aquela que não số cuida do lar, em todos os seus aspectos, mas que também é responsável pela vida emocional do marido e dos filhos.

Os fatores distintivos nas revistas são a maior ênfase que Nova dá aos temas de sexualidade e de vida profissional.

Além disso, Nova enfatiza muito mais o que sua editora mulher e sua equipe produz enquanto revista. São inúmeros e variados os assuntos nos editoriais que transitam pelos meandros da construç̧ão desse veículo de informação de mulher para mulher.

Retornando à dicotomia mundo doméstico versus mundo externo ao lar, observa-se que o mundo doméstico está subdividido nas matérias sobre famíla, casa, casal e economia doméstica.

Isto nos mostra que, apesar da proposta, principalmente da Nova, de catapultar a mulher para fora de sua casa, ainda existe em ambas revistas uma série de matérias que visam locá-la na residência.

Ambas revistas analisadas investem vários artigos para tratar questões domésticas, como por exemplo:

em Claudia: os cuidados com as crianças, pesquisa sobre familia brasileira e sexualidade constituem fatores que tornam um casamento feliz;

em Nova: são as dificuldades afetivas no relacionamento entre homens e mulheres, e a nova ima- gem da mulher que dificulta a aproximação dos homens, além de pesquisa sobre sexualidade feminina.

De maneira geral, os meios de comunicação dâo à mulher uma imagem estereotipada. $O$ aspecto profissional fica em segundo plano. Negado este aspecto da realidade, $o$ jornalismo feminino ajudaria a conservar a situação na forma como ela tem se apresentado ao longo de tantos anos.

Nas categorias e subcategorias do tema mundo doméstico, a característica da mulher como cuidadora/ responsável pelos seus se repete. Propaga-se um papel de mulher ainda identificado com costumes tradicionais, que herdamos de nossas avós e bisavós.

Por exemplo, o assunto sexo também aparece estereotipado; Claudia, vem há décadas apresentando artigos de cunho sexual, entretanto, foi na década de 70 que, através de Nova, se passou a falar de sexo mais abertamente. Em parte porque isto representava a proposta da revista, seu "carro-chefe". Mas também porque sexo auxilia nas vendas, é o grande chamariz para qualquer produto e a publicidade abusa deste filão. Além disso, as revistas foram por muitos anos uma das poucas formas de educação sexual a qual as mulheres tinham acesso.

O mundo externo ao lar-o mundo do trabalho profissional-é muito mais ventilado em Nova do que em Claudia.

Em Claudia o trabalho fora do lar ainda parece estar mais associado à necessidade financeira, no sentido de completar salário do marido; em Nova já está associado do desenvolvimento profissional da mulher propriamente dito.

Alguns setores da sociedacle preconizam que a mulher deve trabaIhar apenas devido a exigências financeiras, pois entendem este esforço como inadequadio ao caráter feminino e às tendências naturais da mulher.

Muitos dos conflitos que as mulheres enfrentam atualmente se estenderam por alguns anos, dentre eles a luta entre maternidade e car- 
reira. Provavelmente as exigências que a mulher tenta administrar dentro e fora do lar não serão resolvidas nos próximos anos.

As mudanças são lentas, apesar do maior envolvimento da mulher no mercado de trabalho, o que auxiliou a redefinir seu status social e também serviu para balançar as referências morais dominantes a despeito dos progressos no campo profissional. Mesmo assim, o sistema de dominação se estende aos nossos dias na forma de desigualda. des e através da divisão sexual do trabalho observada também na dupla jomada feminina.

Outros elementos encontrados nos editoriais, tais como política e economia, fornecem dados que apontam muito mais para o rumo das diferenças entre homens e mulheres do que um caminho igualitário.

Os temas de política e economia, classificados como externos ao mundo doméstico, apesar de terem sido abordados em ambas as revistas, mantêm o tom de que Claudia é para a mulher tradicional - o que implica a dicotomia artificial mulher do lar versus mulher profissional.

Política é um assunto pouco destacado em ambas as revistas. Em Claudia fala-se em político de grande poder e em mulheres que exercem cargos na política, bem como a figura de uma primeira-dama. Ou seja, o assunto é tratado de forma distante, pedestalizada, enquanto que em Nova, o tema desenvolve-se no sentido da leitora como uma força política, ao abordar o assunto da perspectiva do poder da cidadã pelo voto, ou seja, algo acessivel à mais comum das mortais.

Oterceirogrande grupo temático que foi analisado concentra-se na própria revista comentada pela editora, que ocupa um espaço importante e denota extrema preocupação com o próprio umbigo, e apresenta um tom coloquial, de conversa de comadre, amigas intimas.

$\mathrm{Na}$ década de 50 , consolida-se a aliança consumo/imprensa feminina, devido ao desenvolvimento das indústrias relacionadas à mulher eà casa, bem como devido ao fortaleci- mento do mercado interno e à ampliação da classe média. A revista foi se tornando, na passagem dos anos, o veículo por excelência da imprensa feminina, seja no aspecto concreto de sua representação gráfica ou nas formas de estrutura de seu conteúdo. Para além das informações da atualidade, a revista feminina contém informações persuasivas publicitárias e parapublicitârias-bem como informações utilitárias.

As revistas são uma forma popuJar de distribuir informações atualizadas e cultura, pois os livros, na maioria das vezes, não atingem o grande público.

Estudar esses temas atende a uma necessidade de exorcizar um sentimento de inconformismo com a qualidade de vida de mulheres e homens, ambos prejudicados pelos ditames da própria sociedade que criou e perpetua, através da educação formal e informal, papéis tão tradicionais e distanciados. Ao apontar estas dificuldades, existe um anseio explícito de que elas possam ser superadas, transformando idéias em gestos.

\section{REFERANCIAB migliogifaricas}

BARDIN, L. (1977). Anślise de Conteúdo Lisboa: Ediç̧ós 70

BUITONI, D. S. (1986). Imprensa Faminina. Săo Paulo: Atlas.

FRIEDAN, B. (1963). The Feminine Mistique. New York: Norton.

KUDE, V.M. M. (1994), O Mito da Culpa Materna. In: CARDOSO. R. (Org.) É ums Mulher... Petrópolis: Vozes. 123-137.

MALHEIROS, F. (1994). Os Leços Conjugais o os Novos Rumos da Família. In:

CALLIGAFIS, C. et al. Laco Conjugal. Porto Alegre: Artes e Ofícios, p.65-77.

MASCARO, S. de A. (1982), A Revista Feminina: Imagem de Mulher. Dissertaço de Mestrado. Sāo Paulo: ECAUSP.

NOVELINO, A [1988). Maternidade: um Papel Idealizado. Cademos de Pesquisa. 65: 21-25.

PAIVA, V. (1990). Evas, Marias, Liliths... As Voitas do Feminino. Sāo Paulo: Brasiliense. ROCHA-COUTINHO, M.L. (1994). Tecendo por trís dos Panos: a Muther Brasiteira nas Releçóses fomiliares. Rio de Janeiro: Rocco.

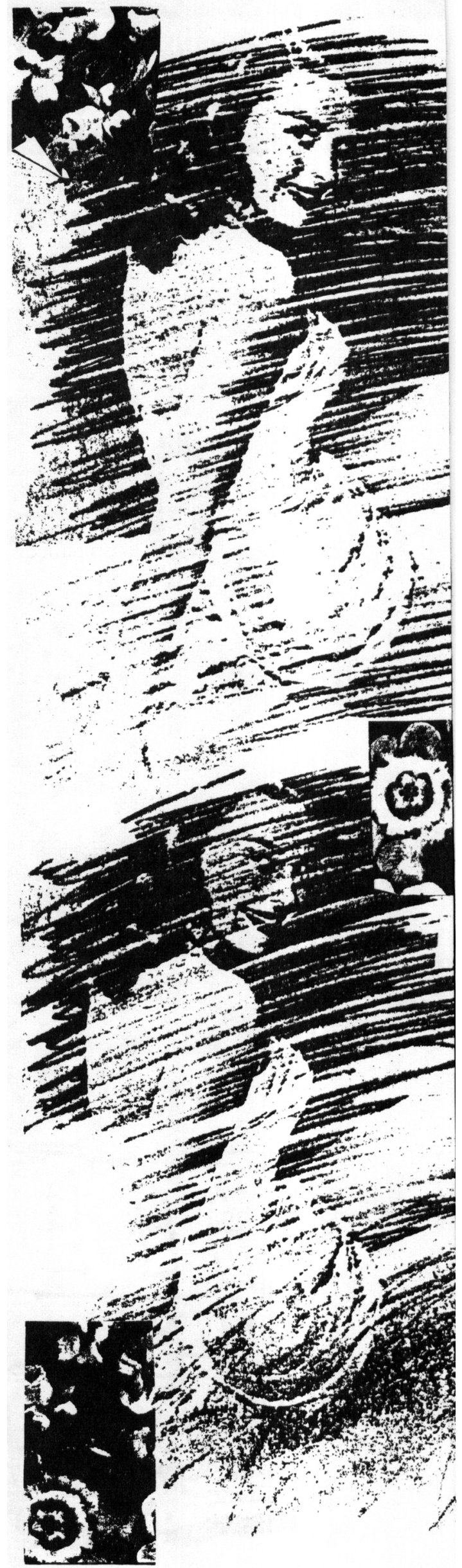

